\title{
III.
}

\section{Studien über Gefässveränderungen in der erkrankten Mittelohrauskleidung.}

\author{
Von \\ Prof. Dr. Adam Politzer \\ in Wien.
}

Unter den pathologischen Veränderungen im Mittelobre sind es vorzugsweise die feineren Gewebsveränderungen der Mittelohrauskleidung, welche das Interesse des Otologen in Anspruch zu nehmen geeignet sind. In ihr beginnen jene krankhaften Veränderungen, welche nicht nur durch die Entwickelung von Schallleitungshindernissen häufig die Hörfunction beeinträchtigen, sondern nicht selten durch Uebergreifen auf lebenswichtige Nachbarorgane die Existenz des Individuums gefährden.

Die mikroskopische Untersuchung der Mittelobrauskleidung: bietet mannigfache Schwierigkeiten dar. Schon im normalen Zustande ist sie an gewissen Stellen der Trommelhöhle, namentlich an der riffigen unteren Wand, sowie an der oberen Wand der Trommelhöhle schwer darstellbar. Am leichtesten lässt sie sich in grösserer Ausdehnung mittelst einer spitzen Präparirnadel v̇om Promontorium ablösen, weil das Gewebe mit der meist glatten Knochenfläche locker verbunden ist und nur zuweilen längs des Verlaufs der Jacobson'schen Anastomose fester adhärirt.

Die leichte Verschiebbarkeit des Promontorium-Ueberzuges erleidet häufig selbst bei chronischen Mittelohrprocessen keine Veränderung, ofters jedoch ist der sehniggraue glänzende Ueberzug durch neugebildetes Bindegewebe verdickt, auch mit der Knochen- 
fläche des Promontoriums so fest verwachsen, dass deren Lostrennung von der Knochenfläche nur schwer gelingt.

Der mikroskopische Befund des Promontorium-Ueberzuges zeigt schon im normalen Zustande bezuiglich des Verlaufes der Gefässe, der Nerven und der Lymphgefässe mannigfache Verschiedenheiten. Der Promontorium-Ueberzug beim Kinde ist. meist wulstiger und gefässreicher und besitzt häufig fingerförmige und kugelige Papillen, wie sie so hänfig am kindlichen Trommelfelle gefunden werden. Bei Erwachsenen hingegen ist der Ueberzug sehr zart und dünn wie ein seröses Häutchen, und sind häufig Gefässe und Nerven ohne vorherige Behandlung.des Präparates mit Goldchlorid und Ueberosmiumsäure nur schwer oder gar nicht aufzufinden.

Auch bei pathologischen Veränderungen der Mittelohrauskleidung begegnet die Untersuchung häufig erheblichen Schwierigkeiten bei der Erforschung der feineren Structurverhältnisse derselben. Dies gilt namentlich von Flächenpräparaten, wo die Epitheliallage durch mehrfache Uebereinandersehichtung verdickt, durch feinkörnige Molecularmasse und Pigment getrübt und undurehsichtig wird, und wo das Gewebe selbst durch Exsudat- oder Pigmentmassen getrübt ist. Es ist daher sehr wichtig, jedes Flächenpräparat nicht nur von der Epithelialseite, sondern auch von der der Knochenfläche anliegenden Seite zu untersuehen, weil man im letzteren Falle sehr häufig die in den tieferen Schichten verlaufenden Gefässe und Nerven genauer und besser untersuchen kann, während dieselben von der Epithelialseite aus nur undeutlich oder gar nicht gesehen werden können,

Ergiebt die Untersuchung am Flächenpräparate kein Resultat in Bezug auf Beschaffenheit des Bindegewebsstratums, der Gefässe and Nerven, so ist das Präparat durch einige Tage in verdünnter Chromsäure zu erbärten und die Untersuchung an feinen auf die Fläche des Präparates senkrecht geführten Durchschnitten vorzunehmen. Wir müssen jedoch bemerken, dass die Behandlung: der pathologischen Präparate mit Goldehlorid oder Osmiumsäure nur selten angewendet werden darf, weil die Gefässe und Nerven durch diese Agentien so alterirt werden, dass die feineren Strueturveränderungen an denselben nicht mehr erkennbar sind.

Die pathologischen Veränderungen in den Blutgefässen der Trommelhöhlenanskleidung (die Untersuchungen beziehen sich zunächst auf die Veränderungen bei eitrigen mit Perforation des 
Trommelfells verbundenen Mittelohrentzündungen) erscheinen am auffälligsten in den venösen Verästelungen. Während man nämlich die arteriellen Gefässe in den meisten Fällen von Hyperämie der Trommelhöhlenauskleidung in geringerer Anzahl und nur mässig ausgedehnt findet, erscheinen die venösen Gefässe in ungleich grösserer Anzahl. Einzelne Stämme derselben sind um das Vielfache ihres ursprünglichen Lumens erweitert, zeigen einen stark gewundenen Verlauf und besitzen stellenweise buchtige Ausdehnungen. Sie bilden namentlich bei starken Aufwulstungen der Mittelohrauskleidung ein dicht gedrängtes Gefässnetz, und es kann kaum einem Zweifel unterliegen, dass, namentlich bei chronischen Entzündungsprocessen, nicht selten Gefässe neuer Bildung in der erkrankten Mittelohrauskleidung entstehen. Die Wandungen der Blutgefässe zeigen öfters Veränderungen in der Structur. Sie sind entweder triib und verdickt, von körnigem Exsudate durchsetzt und pigmentirt; ihr Lumen ist mehr oder weniger mit Blutkügelchen erfüllt oder sie sind stellenweise verdünnt and dadurch partiell erweitert. Zu den seltenen Befunden gehören die Veränderungen in den Lymphgefässstämmen der Mittelohrauskleidung und wollen wir im Folgenden den mikroskopischen Befund eines Präparates mittheilen, einem Falle entnommen, den wir wäbrend des Lebens untersucht und beobachtet haben.

Das Präparat, an welchem ich die angedeutete Veränderung im Ueberzuge des Promontoriums beobachtete, rührt von einer an Phthisis pulmonum auf der Klinik des Herrn Primarius Dr. Scholz verstorbenen 48 jährigen Fran her. Sie litt seit fünf Jahren an einer rechtseitigen Otorrhoe, welche in den letzten Monaten geringer wurde. Die Untersuchung zeigte eine ausgedehnte Zerstörung des Trommelfells, so dass die untere Hälfte des Hammergriffs von Trommelfellsubstanz entblösst in die Perforationsöffnung hineinragte, während von der oberen Hälfte des Griffs die getrübten Reste des Trommelfells bogenförmig in den schmalen sichelförmigen Rest der seitlichen und unteren Peripherie des Trommelfells übergingen.

Durch die Lücke, welche mehr als die Hälfte des Trommelfellareals einnahm, sah man den feuchtglänzenden röthlich-gelben Ueberzug des Promontoriums; die Ohrtrompete beim Valsalva'schen Versuch durchgängig. Die $\mathrm{Uhr}$ wird auf $10 \mathrm{Ctm}$., die Sprache in der Entfernung von 6 Meter gehört; die Perception von den Kopfknochen beiderseits gleichmässig vorhanden, die 
Vibrationen der Stimmgabel werden von der Medianlinie des Schädels auf dem erkrankten Ohre stärker percipirt.

Bei der nach dem Tode vorgenommenen Section des Gehörorganes war der Defeet am Trommelfelle übereinstimmend mit dem wäbrend des Lebens beobachteten Befunde. Die unteren und seitlichen Ränder der Perforationsöffnung waren durch die peripheren dicht zusammengedrängten Circulärfasern gebildet. Am freistehenden unteren Ende des Hammergriffs findet man bei Lupenvergrösserung noch zackige Reste von Trommelfellsubstanz; die Gelenkflächen des Hammers und Ambosses sind gegen einander leicht versehiebbar, der Steigbuigel im ovalen Fenster beweglich.

Der gelbliche Ueberzug des Promontoriums lässt sich mittelst einer spitzen Nadel auf der knöchernen Unterlage leicht verschieben und ablösen. Bei der mikroskopischen Untersuchung findet man die Oberfläche dieses Ueberzuges von einer mächtigen Lage theils rundlichen, theils eckigen Plattenepithels bedeckt, deren Inhalt ausser dem stark markirten Kerne stellenweise aus Fettkörnchen und moleculären staubförmigen Körnchen besteht.

Durch die mehrschichtige Epitheliallage werden die in den tieferen Schichten des Promontoriumüberzuges lagernden Gewebselemente gedeckt und sind mit dem Mikroskope kaum unterscheidbar. Wird jedoch das Präparat am Objectträger so umgewendet, dass die das Promontorium berührende Fläche des Ueberzuges dem Auge zugewendet ist, so sieht man die im Bindegewebsstratum verlaufenden scharf markirten Gefässe und Nerven.

Die Fläche des Präparats zerfällt in zwei Regionen. In der vorderen gegen das Ost. tympan. hinziehenden Region sieht man mehrere stark gesehlängelte, stellenweise erweiterte, mit Blutkörperchen gefüllte Blutgefässe, augenscheinlich venöser Natur. In der Nähe eines grossen Gefässstammes verläuft ein starker Nervenast, weleher sich mehreremale dichotomisch verzweigt, wobei die Aeste nur stellenweise dem Verlaufe der Gefässe folgen. Auffallend ist das an der Theilungsstelle beginnende gänzliche Fehlen des Nervenmarkes in einem Aste, an welchem man bloss die Contouren des Nervenastes ohne jeden Inhalt sieht.

An der hinteren, zwischen dem ovalen und der Mitte des runden Fensters gelegenen Region des Präparates sieht man einen abnorm erweiterten Lymphgefässstamm, dessen Verlauf und Verästelungen durch die beigefügte Abbildung (Fig. 3) wiedergegeben sind. An dem gleichmässig weiten Stamme $a$ entsteht eine kreis- 
förmige buchtige Ausdehnung, oberhalb welcher senkrecht vom Stamme zwei blind endigende fingerförmige Abzweigungen $s s$ ausgehen. Im weiteren Verlaufe gehen nach einer Seite hin mehrere kleinere blindsackförmige Ausläufer $b \quad b \quad b$ vom Stamme ab. Unterhalb dieser erweitert sich plötzlich das Lumen zu einem bedeutenden unregelmässigen Reservoir $(r)$, dessen Contouren zwar eine scharfe Begrenzung zeigen, welches aber wahrscheinlich mit mehreren benachbarten Räumen $l l$ von analogem mikroskopischen Baue communicirt.

Das Lumen des beschriebenen Lymphgefässes wird von einem scharf contourirten, sehr zierlichen Epithel ausgekleidet, welches stellenweise normal, an anderen Stellen hingegen ron feinkörniger Molecularmasse und kleinen Fettkügelchen erfüllt erscheint. In der Nähe dieses grossen und erweiterten Lymphgefässstammes befinden sich nach vorn zu mehrere kleinere anscheinend blind endigende Lymphgefässstämme ohne seitliche Ausläufer, welche in ihrer Structur mit dem beschriebenen grossen Lymphgefässstamme übereinstimmen. Einmal fand ich in neugebildetem Bindegewebe der Trommelhöhle Lymphgefässbildungen von analogem Baue mit seitlichen Ausläufern in einem Falle, wo der obere Abschnitt des Trommelhöhlenraumes in Folge eines chronischen Eiterungsprocesses im Mittelohre von einer succulenten, den Hammerkopf und den Amboss einhüllenden neugebildeten Bindegewebsmasse (wuchernde Schleimhaut der Autoren) ausgefullt war. 